\title{
The Impact of Economic Policy in Increasing the Value of Human Capital Stock in Albania
}

\author{
Academic Prof. Dr. Anastas Angjeli \\ Dr. Niko Pano \\ Mediterranean University of Albania
}

\begin{abstract}
This paper raises the question: "How much the economic policy of the government affects the growth of the value of human capital stock in Albania". It does a survey of four key elements of the government's economic policy in recent years, namely: the employment policies, the education policies, health care policies, and state insurance policies. The analysis of the expenditures and investments made in these areas enables to reveal the direct and indirect relationship of these elements to the indicator 'value of the human capital'. In the methodological aspect, the research is based on the classic forms of assessing how the social and health policy does impact the value of the human capital stock. The study distinguishes the relevant benefiting age groups, focusing particularly on the ages of 7-24 for the impact of education; ages 65-85 for social and health insurance policies and ages 45-55 for employment stimulation policies. This choice comes from the fact that the budgets related to these policies have been drafted taking in consideration the above-mentioned social groups. Consequently, efforts have been made to approximate the Albanian statistical calculations according to the J-F protocol algorithm, with the dynamics of these policies in the last 6 years.
\end{abstract}

Keywords: Value of capital stock, employment reforms, opening of health market, development multiplicator, Happiness economics

\section{Introduction}

Among the most novel indicators that determine the development potentiality of an economy is "the value of the human capital stock". There are many macroeconomic recommendations that this indicator should be considered as an important standard of a country's national statistics, because it calculates a potential development trend of a generation and of a whole nation over time. Nowadays it has become a prominent indicator of importance in the actual assessment of a society, as well as an indicator of its potentiality for development. 


\section{Journal of International Cooperation and Development}

www.richtmann.org/journal

Vol 2, No 2, November 2019

\section{Historical Development of the Concept}

The concept of human capital is ancient in the theory of economic thought, although its numerical evaluation has been introduced only in the last decades. It became especially important after the 2000s when it was officially classified as an indicator not only of economic development, but of social welfare too.

Among different designations of this concept, we follow the definition made by the Organization for Economic Co-operation and Development in the 2001 treaty, which describes it as follows:

"Human capital is considered to be the entirety of man's individual knowledge, skills, competencies and attributes that facilitate the creation of personal, social and economic well-being." $(O E C D, 2012)$

At a first glance it appears that human capital is a product of individual and genetic features of humans. Nevertheless, all the surveys reveal that in some way it is not only a genetic element but also social production that, like all forms of capital, is accumulated and increased (Schultz, 1961). It is this feature that associates this concept firstly with education, employment, social policies of the government for social and health protection. In this aspect, it is one of the key elements related to the government development policies on one hand and market dynamics on the other. Because of the relations with the governmental development policies, its own dynamics expresses the potential of a country's market development as well as the growth of the set of parameters of quality assessment of its citizens' lives.

Over the past 20 years, the economists' efforts to set up various macroeconomic indicators which determine the degree of satisfaction of a country's population have been increasing (Gibson \& Oxley, 2006), (Li, 2010), (Liu, 2011). There are different theories evolved about this, but everyone recognizes a prominent difference between the value of the stock of human capital and the level of social satisfaction of a country's population. If the first concept is represented by a number and there is a certain protocol for measuring it, there are many attempts to calculate the second one, but there is still a lack of a measurement protocol approved by the relevant institutions and an international comparison base.

The concept of social happiness is widely treated in social psychology as a perception of the satisfaction level of the population in a given country. As declared by Stiglitz (Financial Times, 2009), the French President Nicolas Sarkozy established a commission with eminent economists conducted by Nobel laureate Joseph Stiglitz to develop other economic indices of happiness outside the classic concept of GDP or "Human capital stock value". This commission did take into account a new indicator called GDH (Gross Domestic Happiness) that has been used in the state of Bhutan, in the Himalaya to replace the GDP and that was considered by the Prime Minister Jigmi Y. 


\section{Journal of International Cooperation and Development}

www.richtmann.org/journal

Vol 2, No 2, November 2019

Thinley as of a greater importance than the economic indicators. (The Guardian, 2012).

GDH (Gross Domestic Happiness) is an indicator for which there is no defined assessment protocol, but everyone accepts that it is related to four key elements:

- The ecologically supported sustainable development

- The development of education as a function of rising social conscience

- The extinction of fear and the re-conception of freedom

- The evaluation of time as a function of perspective.

Among the four above mentioned indicators none of them is of pure economic sense. However, these indices indirectly do assess the civic behavior influenced by external economic elements. The only conclusion the "Sarkozy Commission" could draw was that in the countries where the public administration worked better, the population felt happier. The comparison between the "Human Capital Stock Value" and the GDH (Gross Domestic Happiness) is done not only to figure out new statistical evaluation systems of economic developments, but also to analyze the historical difference of a protocolled indicator with a non-protocolled but evidenced one. The measurement of the indices related to the development potentials and the level of civic satisfaction is a signal of the change in the classical economic assessment, as well as a sign of the expansion of the economic progress concept.

\section{Methodology}

Many researchers nowadays do dedicate an important attention to the "Human capital stock value" among others, when analyzing factors and development opportunities. According to literature sources (WB, 2007), (Nosvelli, 2009), the World Bank for the first time made evident in $\mathbf{2 0 0 6}$ four methods for calculating the value of human capital as follows:

- Calculation based on the cost of education. (cost-based)

- Calculation based on the ability to generate income. (income-based)

- Calculation based on the effectiveness of the education process (all levels)

- Calculation based on the cost of raising and educating children aged 0-26.

After 2008, many countries have engaged special public units to calculate the value of human capital and all accepted the so-called Jorgenson-Fraumeni protocol (known as the JF method), which is an analytical calculation of the incomes generated by the individual for all working years at full value (full labor compensation) (Jorgenson \& Fraumeni, 1992a, 1992b). A better understanding of this methodology can be achieved considering these key elements:

To calculate a person's life cycle in the methodological aspect of the study, in countries where the retirement age is determined by law, the population is classified as follows (as the value of human capital stock):

- Age group 0-4 years old, where there is neither education nor employment 
- Age group from 4 to 15 years old, where it's education only

- Age group from 16 to 40 , where it is education and work

- Age group 40-67, where it's only work

- Age group over 68 , where it's only retirement.

The above age groups are classified as the life span corresponding to working age and the time of life outside the labor market. Since the first and second groups are out of the labor market/ working age and do not generate incomes, the calculation of the value of human capital stock is impossible with the income method. Consequently, it is generally accepted that direct calculation of capital stock value should consider the population of group 16-67 years old and over 68 , for the incomes from pensions.

To approximate the calculations in respect to the methodological use of the formula, it is more correct to divide the age group 16-40 from the 40-67, because for the first one there might be education and job as well, while for the second age group there is only job during that part of the lifespan. This means that we have two different algorithms for these age groups and two different scores in terms of value.

$>$ All algorithms used in the estimation of the stock of human capital belong to the descending system from the highest level. For instance, for a 75-years old person (average life span), the income of the 75'th year of life in the calendar year 2017 is $A$, while those for 2018 (next year) is equal to zero. For a 74 years old income in 2017 is A, while in 2016 it is B. For a 73 years old income for the next two years are $A+B$ and $C$ for the year 2015. Following this system all the groups with the same level of education, but different ages have an individual value with the real income of the current year and a future income value equal to the oldest people in the same education group. This formula is valid to measure the value of the human capital stock in 2017 for all persons in a country that in that year range from 0 to 75 -years old, where the value of the 75-years old stock is added to the one of the 74 years old and so on.

This is presented in the following formula:

$L I N_{a g e}^{e d u}=E M R_{a g e}^{e d u} * A I N_{a g e}^{e d u}+S U R_{a g e+1}+\operatorname{LIN}_{a g e+1}^{e d u}\{(1+r) /(1+\delta)\}$

$L I N_{a g e}^{e d u}$ - is the present value of income from work, for individuals with education level (edu), at age(age) as the amount of expected income realized in the working life cycle;

$E M R_{a g e}^{e d u}$ - is the level of employment of persons with education level (edu) at age (age);

$A I N_{a g e}^{e d u}$ - is the actual income (as income statement) for individuals with education level (edu) at age (age);

$S U R_{\text {age }+1^{-}}$is the probability to live a year longer (age +1$)$; 


\section{Journal of International Cooperation and Development}

www.richtmann.org/journal

Vol 2, No 2, November 2019

$L I N_{a g e+1}^{e d u}$ - is the present value of income from work for an individual with the same level of education but one year older;

$r$ - is the forecast of the annual growth rate of future labor income (in real terms) for a person with these characteristics

$\delta$ - is the forecast of annual inflation rate in the future (in real terms).

The protocol for measuring the value of the human capital stock considers not only the labor income (generated during working time), but also the income generated by the productive exploitation of hours beyond work time (off-labor income). The methodology in this case is even more complicated and is calculated using the relationship of the two elements wage / revenue in off-labor activities. The methods mostly used for this calculation, according to economic literature, are:

1. Opportunity Cost Method (indirectly measurable)

2. Replacement Cost Method (comparatively measurable).

The opportunity cost method relies on the principle of assessing the added value of working time (which determines market income) that is conditioned by use of nonworking time. For instance, physical exercise (non-work time) potentially influence working time with an increase in productivity. Hence, even though no direct income is generated for this time-period, additional income is generated at the working time. Theoretically, health welfare (as the value of rest time) at worst is equal to the value of the work productivity increase. In fact, this method is nothing more than a way of finding an indirect equivalent assessment for an element that can't be directly assessed. Consequently, it bears all the error' elements that contain the statistical methods of calculation based on comparative evaluation methods (J \& F, 1992a, 1992b).

The replacement cost method relies on another valuation, namely the assessment of the outcomes from off-labor market activities by the possible cost of its realization from a market subject that provides this service. The hours a person uses for house chores can be estimated by the value of a housemaid, or the value of the working time a person spends to make a hydraulic adjustment at home is equivalent to the cost of paying a plumber for this job (d'Ercole, 2012), (Liu, 2011).

The above methods both require statistical data relating to the use of leisure time, which might be provided by complex surveys based on age, the level of education, gender and other characteristics of the population.

Using the above-mentioned protocols and many highly-polled surveys and studies in this regard, many developed countries have determined the value of the human capital stock over a given period of time. It is a common use that the key factors determining the level of human capital value of a country are:

$\checkmark$ Educational level and professional qualification of the population realized at certain milestones of the working cycle.

$\checkmark$ The level of health care and life quality indicators of a country's population.

$\checkmark$ The level of economic development and its standard evaluation indicators. 


\section{Journal of International Cooperation and Development}

www.richtmann.org/journal

Vol 2, No 2, November 2019

The population structure, its average age and the probability of extending the life cycle.

$\checkmark$ Social and employment policies and the creation of facilities for the initiation and consolidation of new businesses.

The above discussion tried to present the methodology for human capital measuring under the J \& F protocol and factual forms of calculating this indicator from the specialized institutions in developed countries. Albania is missing this experience. INSTAT (Institute of Statistics) has not yet taken real steps to calculate the value of human capital stock, consequently any effort to make such calculation does not comply with any relevant protocol.

\section{Efforts to Calculate Indirectly the Value of Human Capital Stock in Albania Develop of an Alternative Indicator}

Human capital stock value in Albania has not yet been calculated and the implementation of the measurement protocol of this indicator has many difficulties, not only related to the application of measuring algorithms but also to the definition of the data which can be included. The inability to complete all the data of the J \& F formula for estimating the stock of human capital, has encouraged us to the development of an indicator that comes closer to the value of human capital stock, but it is not rigorously calculated with the protocol of this indicator as above described. The attempts are done to compile an indicator that could reflect how much income an Albanian individual could generate throughout his/her life.

The first question raised related to the concept of the value of human capital stock is: "How much income a 29-year-old average citizen in 2017 will earn for the next 38 years until he retires?" We have chosen the 29-year-old because in the statistical classification of labor force participation defined by INSTAT the population is classified in two groups: 15-29 years old and 30-67 years old (INSTAT, 2018). The first group consists of persons who have a job and study, whereas in the second group people are mainly only working. On the other hand, according to the existing laws in 2017, the retirement age in Albania is 67.

The second question is: "How much income do Albanians aged 16-29 years generate?" The method of calculating the potential earnings that this group generates is related to the age group methodologies that study and work at the same time. The analysis below has used data from INSTAT related to students enrolled in public and private secondary education schools, and higher education at the first and second levels of study. Participation in the workforce of this group is already analytically determined in the relevant labor force survey calculated by INSTAT.

The third question is: "How much income do Albanians make by the time they retire to the age of 75 ?" In answering these questions, we have taken into account the average 


\section{Journal of International Cooperation and Development}

www.richtmann.org/journal

Vol 2, No 2, November 2019

pension any Albanian retired in 2017 gets, and the amount received in the same year by those who get pension in their 75-th year of life.

The fourth question is: "Is it possible to determine the value generated by Albanians aged $0-16$ years based on the social costs of raising this age-group?".

Our estimation of the indicator that indirectly assesses the potential of the Albanian population to generate income during its life will be supported by the following judgement and argumentation:

1. Regarding the group of 16-67 years: the degree of participation in the workforce of the Albanian population as per the INSTAT classification for the 16-67 age group, is reported through a two-step division, 16-29 and 30-67 years old. The participation of the first age-group in the labor force from 2015 to the end of 2018 is on average $46.5 \%$, while for the second age-group it is on average $76.5 \%$ for the same period. The Labor Force Surveys, Tr.1.2015-Tr.4.2018 published by INSTAT, announces that participation in the working force for the population group 15-67 is on average 66.4\% (INSTAT, 2018). Based on this data and estimating the fact that in the classification of our system for both groups we do not have analytical data on the average salary level for each group, we have made all the calculations by mean of an average level salary. Since the participation level/ percentage in the labor force for these groups is different, the value of the labor income for the demographic range of these groups will be different. Specifically, for the age group 16-29, only 5 out of 10 people work and the income of 5 persons as an estimate of the group's earnings is distributed to 10 persons, whereas for the age group of 29-67, there are 8 out of 10 people that work, and their income is distributed to 10 . Therefore, even if the average salary is equal between both groups, the income value generated by each group is different. In this respect, we have partial compliance with the J \& F algorithm, even though this compliance is not based on the figures, but on the methodology.

2. Since the basis of our calculation is a 29 -year-old citizen in 2017, the indicator that will be derived from this study is a value that belongs to this year. In this respect, the potential earnings of this 29-year-old citizen will be calculated until retirement based on the average salary of this year, the average annual pension of that year and the average longevity of Albanians in the same year. Thus, starting from the average salary of 2017, we should calculate the income from the work of the 29 years old up to 2050, the income of the pensioners up to 2025, the budget expenditures for kindergartens from 2012 to 2017 and the budget expenditures for education and health in 2005-2017.

3. The calculations are based on the number of Albanian people living in the country, as determined by INSTAT in 2017. The time value of money is considered in order to calculate the income that can be provided with the 


\section{Journal of International Cooperation and Development}

www.richtmann.org/journal

Vol 2, No 2, November 2019

average salary of a 29 -years old by year 2050 . It has been processed with the macroeconomic parameters defined below.

4. The underpinning to our calculations were some data for the next 30 years that are important for the progress of the Albanian economy, more specifically:

- The average annual growth of the Albanian economy for the next 30 years is 1.3\%. (INSTAT, 2018).

- The average rate of inflation for the next 30 years is $2.8 \%$. (Celiku et al., BSH, 2010)

- Long-term treasury bill interest for the next 30 years is 6.3\%. (Cani \& Haderi, BSH, 2002)

These forecasted indicators are provided from studies conducted by governmental entities or prominent Albanian specialists and they have derived from well-known statistical methods.

5. In order to compile a statistical indicator comparable to the concept of the value of human capital stock by age groups, we have calculated the income that Albanians can generate in 2017 as follows:

- Based on the average salary of 2017, according to the time value method we have calculated the probable income of a 29 years old until his/her retirement age that by law was 67 .

- Based on the average pension level in 2017, according to the time value method we have calculated the probable income of a 67 years old until the 75th year of his/her retirement.

- After correcting the average salary according to the participation in the working forces of the age group 16-29, we have calculated the expected income of this age group and added this value to the budget and private expenditures for the high and higher education for the years 2004-2017 divided by number of pupils and students.

- For the age group 0-5 years we have used the comparative cost method according to the level of budgets for private and state pre-school education for the years 2012-2017.

- For the age of 6-16 we have calculated the incomes according to the comparative cost estimates of primary education (9 years of education) expenditure for the years 2012-2017 divided by the number of pupils.

Based on the above data, the indicator for "human capital stock value" in Albania for 2017 is approximately 16,250,000 Leke (ALL). This is a totally personal assessment that will certainly change with the perfection of the measuring systems of this concept. We do not pretend to provide the accurate value of human capital stock in Albania, but to approximate a figure that can create the idea of the value of this indicator. In this respect, the number resulting from our estimates falls into an interval of plus - minus 


\section{Journal of International Cooperation and Development}

www.richtmann.org/journal

Vol 2, No 2, November 2019

$10 \%$, which is affected by the potential change of the above-mentioned factors and the probability of their impact.

\section{Study Limitations}

We defined at the beginning that this is the first attempt to compile an indicator that serves the meaning of "the value of the stock of human capital in Albania". The main elements that limit the study methodology and its result among others are:

a) The age groups defined by our calculating system can't be fully matched with those of the J \& F algorithm, but the calculating character is incorporated. It is true that the income tax calculations have not taken into consideration the inequalities of income that come from the educational level. It was almost impossible to add this factor to our calculations. Until today in Albania, there are no analytical data which correlate the degree of education to wages. We accept that this calculation has an error degree, which is higher for the group of 16-29 years old, whereas for the group over the age of 50 is much less sensitive. Once work experience becomes an important element of the work value, the impact of the education factor is far less significant.

b) Taking the average salaries as the basis of income from work, we have actually seen the direct impact of age on wages, but on an average level. This does not mean that the same person named A.B. who was employed in 2001 in the private sector, earned a wage of 13,355 Lek (ALL) and in 2018 this same employee had a monthly salary of 50,589 Lek (ALL). These are data on the average wages and hide the "average error". In this respect, we are biased from the J \& F system, where the income of a 67-years old with $x$ education having $y$ income, means it in real terms in 2017. In our system, the income of the 67years old is calculated as the expected wage of the 29 years old in 2050.

c) If we have a figure that determines the expected value created as income from Albanians for the four age groups, then we can say that we have compiled an indicator that can approximate the economic value of the human capital stock in Albania. Surely, we are dealing with a complicated concept of the time value of money, which is conditioned by the macroeconomic dynamics of the country and several other macroeconomic factors. All these factors will affect the result in different ways and magnitudes and will condition the variation of the value in an interval. Based on a forecast, the real value of the output is more predicted than estimated.

d) The main difference of our indicator from the value of the human capital stock calculated by other institutions is that this calculation is outside the established protocols and tries to create data rather than administer them. This is the difference between calculation and estimation, where the first administers and 
delivers results, while the second creates the data and tries to prove their validity.

\section{The Impact of Government Policies on the Value of Human Capital Stock}

The employment policy has been one of the main factors that has affected the value of human capital in Albania. From 2014 until the end of 2018, there is a gradual increase in the level of employment, but the most positive elements appeared at the end of 2017, when for the first time in the last 20 years the employment growth was higher than the increase of economic growth (Survey of the work force, INSTAT, 2018). On this basis, we can say that the value of human capital stock for the age group up to 45, which is very vulnerable to employment, has risen more than this figure. The main employment factors that influenced the value of the human capital stock are as follows:

- Growth of employment in agriculture in the age group 45-55. Agricultural sector development was extensive but also intensive, especially in some products where export growth focused on agricultural capital and investment in production tools. The development of agriculture, as it occupied most of the workforce, curtailed the phenomenon of internal migration and alleviated social problems in the village.

- Boost to the formalization of the economy. Changes in the tax system by business structures not only restricted informality in the Albanian business, but also limited the possibility of informality in the labor market. In the last two reports of the Labor Inspectorate, for 2016 and 2017, there is a significant reduction in informality that directly has increased the estimated income of the population (Labor Inspectorate, 2017, 2018).

- Compiling policies that stimulate the growth of innovative ventures with Guarantee Funds for all those individuals or businesses that sought to enlarge their business. This policy had the main purpose to stimulate mostly the business activity in the field of production with the aim of enabling systematic industrialization of the country and internationalization of Albanian businesses. A faster growth of medium and large businesses in the last two years has undoubtedly brought about a positive pressure on consumer growth as well.

Another factor that led to the increase in the value of human capital stock in Albania has been government policy related to vocational education and active employment policies. Several elements have had vital influence, precisely:

- During last years a major development occurred in the vocational education. Both the number of vocational schools and the number of students attending them was expanded. Data from the MASR indicate that only in 2017, compared to 2016 , vocational schools increased by $40 \%$ and the number of students by $45 \%$ (MASR, 2018). The full effects of this policy will be noticeable in the coming 


\section{Journal of International Cooperation and Development}

www.richtmann.org/journal

Vol 2, No 2, November 2019

years, but some key tendencies have by now emerged.

- Financing employment policies is another element which reformed the existing employment strategy. The establishment of the Employment and Training Fund, the strengthening of the role of the National Labor Council, the establishment of the National Council for Employment and AFP, the establishment and functioning of sectoral committees were important steps to strengthen the governance of the labor market. The new organization of labor offices restructured the use of funds for active employment policies and changed, especially for the ages 35-45, the value of human capital in Albania.

Another factor that has led to the increase of the value of human capital stock in Albania has been governmental policy regarding public health and public partnership in this regard. It is worth mentioning:

- Public - private partnership in health sector brought about a revolution in the disease prevention system, screening the chronic elements of the population, and defining the main directions of effective health policies.

- Cooperation with the private sector in primary health services and the reform of the medicine financing system led to the reduction of the unit health service costs, but also to the increase in the number of free services. Especially for the 55-65 age group, this influenced the real change in the stock of human capital before retirement.

Another factor that has led to the increase in the value of human capital stock in Albania has been government policy regarding the vulnerable group of individuals and the fight against social diversification. Although these are elements of social culture and every policy applied to them requires time, the first results are particularly noticeable to racial integration in schools and state administration.

In conclusion, we would like to clarify here that the "value of human capital stock" in Albania does not belong to someone in particular, it has no name or surname, but it belongs to the Albanians in general, which we do not divide in rich and poor people, neither in well-educated and non-educated ones, but in happy and unhappy ones.

\section{References}

Cani S., Hadëri S., "Sistemi financiar shqiptar në tranzicion: progres apo brishtësi?" https://www.bankofalbania.org/rc/doc/Banka_e_Shqiperise_ne_dekaden_e_dyte_te_tranzi cionit_Konferenca_III_Kombetare, 2002.

Çeliku E., Kristo E., Boka M., "Modelimi i PBB-së tremujore roli i treguesve ekonomikë dhe atyre

të vrojtimeve" Banka e Shqiperise, 2010. https://www.academia.edu/34848226

/Modelimi_i_PBB_se_tremujore_Roli_i_treguesve_ekonomike_dhe_atyre_te_vrojtimeve

Gibson, J and Oxley, L (2006). A Forward-Looking Measure of the Stock of Human Capital in New

Zealand. The Manchester School, Vol.74, No.5, 593-609.

INSTAT, Studimi i forcave te punes 2018, http://www.instat.gov.al/ 


\section{Journal of International Cooperation and Development}

www.richtmann.org/journal

Vol 2, No 2, November 2019

Istituto Nazionale di Statistica (INS), II Valore Monetario Dello Stock di CapitaleUmano In Italia. Anni1998-2008.

Jorgenson, D.W. and B.M. Fraumeni (1989). The Accumulation of Human and Non-Human Capital 1948-1984 in R.E. Lipsey and H.S. Tice (eds.). The Measurement of Savings, Investment, andWealth. The University of Chicago Press, Chicago.

Jorgenson, D.W and B.M. Fraumeni (1992a). The Output of Education Sector in Z.Griliches (ed.) Output Measurement in the Service Sectors. The University of Chicago Press, Chicago.

Jorgenson, D.W and B.M. Fraumeni (1992b). Investment in Education and U.S. Economic Growth. Scandinavian Journal of Economics, 94, Supplement, 51-70.

Li, H. (2010) Human Capital in China.China Center for Human Capital and Labor Market Research, Central University of Finance and Economics, Beijing. China, October 2011.

Liu, G., Measuring the stock of Human capital for comparative analysis: An application of the lifetime income approach to selected countries. OECD Statistics Directorate Working papers, n.41 (SDT/DOC 2011/6) Paris: OECD.

Mira d'Ercole, M. (2012). I progetto dell'Ocse sulla misura monetaria dello stock di capitaleumano.

Mulligan, C.B., X. Sala-i-Martin (1997). A labor-income-based measure of the value of human capital: an application to the States of the United States, Japan and World Economy. Elsevier, vol. 9

Nosvelli, M. (2009). La misurazione del capitale umano: una rassegna della letteratura. Working paper Ceris-Cnr n.2/2009, Torino: Ceris.

OECD, Approches to measuring the stock of human capital: a review of country practices, Statistics Directorate, working paper No 48/ 23 November 2012

O’Mahony, M., P.A. Stevens (2004). International Comparisons of Performance in the Provision of Public Services: Outcome Based Measures for Education. London: National Institute of Economic and Social Research.

O'Neill, D. (1995) Education and Income Growth: Implications for Cross-Country Inequality.Journal of Political Economy, 103, 1289-1301.

Psacharopoulos, G., A.M. Arriagada (1986). The educational composition of the labor-force.

Schultz, T. W. (1961). Investment in Human Capital. The American Economic Review, 51(1), 1-17.

Stiglitz J., Towards a better measure of well-being, Financial Times, September 13, 2009

The Guardian - https://www.theguardian.com/world/2012/dec/01/bhutan-wealth-happinesscounts

World Bank (2007), World Development Indicators Online, http://web.worldbank.org/ WBSITE/EXTERNAL/DATASTATISTICS/OcontentMDK:20398986 menuPK:64133163 pagePK: 64133150 piPK:64133175 theSitePK:239419,00.html

The World Bank: Pillars of the Human Capital Project-Human Capital at Spring Meetings 2019. http://www.worldbank.org/ 